\title{
Effects of letrozole alone or letrozole in combination with low-dose intramuscular injection of human menopausal gonadotropin on ovulation and pregnancy of 150 patients with polycystic ovary syndrome
}

\author{
Kaiser Ahmad, Ufaque Muzaffar*, Sadiya Bashir, Farhat Jabeen
}

Department of Obstetrics and Gynaecology, GMC Srinagar, Jammu and Kashmir, India

Received: 10 June 2020

Accepted: 08 July 2020

\section{*Correspondence:}

Dr. Ufaque Muzaffar,

E-mail: ufaque3@gmail.com

Copyright: (c) the author(s), publisher and licensee Medip Academy. This is an open-access article distributed under the terms of the Creative Commons Attribution Non-Commercial License, which permits unrestricted non-commercial use, distribution, and reproduction in any medium, provided the original work is properly cited.

\section{ABSTRACT}

Background: Objective of the study was to explore the effects of letrozole (LE) in combination with low-dose intramuscular injection of human menopausal gonadotropin (HMG) on the ovulation induction and pregnancy of patients with polycystic ovary syndrome (PCOS).

Methods: The study comprised of 150 couples who were randomly divided into two groups of 75 each. Group "A" received letrozole (LE) in a dose of $2.5 \mathrm{mg}$ to $5 \mathrm{mg} / \mathrm{d}$. LE was started orally starting on 3rd to 5th day of menstrual cycle for 5 consecutive days. Group "B" received letrozole in a dose of 2.5 to $5 \mathrm{mg}$ /day starting on the 3rd to 5 th day of menstrual cycle for 5 consecutive days. Starting from the day of oral administration of letrozole, 75 IU HMG was injected intramuscularly on alternate days for 5 consecutive doses. The ovulation induction parameters and pregnancy outcomes were observed.

Results: The Group A (LE group) had the most completed cycle (310 cycles), 157 (52.3\%) of which had ovulation. The Group B (LE+HMG) group completed the fewest cycles (258 cycles), with $168(65.1 \%)$ of them ovulating. This difference was statistically significant $(\mathrm{P}<0.05)$. On HCG injection day, both the endometrial thickness $(11.5 \pm 1.2)$ and number of mature follicles $(2.1 \pm 1.3)$ of the Group B were significantly higher than those of Group A $(\mathrm{P}<0.001)$, but the follicle diameters were similar $(\mathrm{P}>0.05)$ The pregnancy rate of the Group B was $54.7 \%$, which was significantly higher than that of the Group A $(29.3 \%)(\mathrm{P}<0.05)$ The average medication cycle of the Group B group was significantly shorter than that of the Group A $(\mathrm{P}<0.05)$.

Conclusions: The regimen using LE in combination with low-dose intramuscular injection of HMG has satisfactory therapeutic effects on ovulation induction, short medication cycle and high clinical pregnancy rate, which is promising for treating patients with PCOS infertility.

Keywords: Human menopausal gonadotropin, Letrozole, Ovulation, Pregnancy, Polycystic ovary syndrome

\section{INTRODUCTION}

Polycystic ovary syndrome (PCOS) is a heterogeneous disorder that is defined by a combination of signs and symptoms of androgen excess (hirsutism and/or hyperandrogenaemia) and ovarian dysfunction (oligo- ovulation and/or polycystic ovarian morphology (PCOM)), provided that other specific diagnoses, such as hyperprolactinaemia and non-classic congenital adrenal hyperplasia, have been excluded. ${ }^{1}$ The prevalence of PCOS in premenopausal women ranges from $\sim 6 \%$ (using the older, more restrictive criteria) to $\sim 20 \%$ (when 
applying current, more inclusive definitions), possibly making this syndrome the most common endocrine and metabolic disorder in women of reproductive age..$^{2-5}$ PCOS is one of the important causes of infertility in females. The condition occurs in about $5 \%$ to $10 \%$ of women accounting for $30 \%$ to $60 \%$ of anovulatory infertility. ${ }^{6}$ There is a spectacular increase in the prevalence of PCOS all over the world especially in Asia. The condition seems to be on a rise in Kashmir valley although systematic studies on the subject are still underway. ${ }^{7}$ Incidence of PCOS is to $20 \%$ worldwide and in India it ranges from 2.2 to $26 \% .^{8}$ PCOS was first described in 1935 by Stein and Leventhal as the combination of hirsutism (a condition of male-pattern terminal hair growth in women), amenorrhoea (absence of menstruation), chronic anovulation and infertility, obesity and enlarged cystic ovaries. ${ }^{9}$ However, it was not until 1990 that the WHO included 'E28.2 Polycystic ovarian syndrome' with sclerocystic ovary syndrome and Stein-Leventhal syndrome as synonyms among the disorders of ovarian dysfunction included in the International Classification of Diseases, 10th revision (ICD10). ${ }^{10,11}$ The economic burden of PCOS is significantly huge. Around 4 billion dollars are spent annually in the United States to screen for the disease and treat its various morbidities, including hirsutism, infertility, and diabetes mellitus. The 'polycystic' appearance of the ovaries frequently found in patients with PCOS is caused by the accumulation of ovarian follicles in different stages of maturation and/or atresia. ${ }^{12}$

Table 1: Criteria for PCOS classification.

\begin{tabular}{|lll|}
\hline $\begin{array}{l}\text { NIH/NICHD (must meet both } \\
\text { criteria) }\end{array}$ & $\begin{array}{l}\text { ESHRE/ASRM } \\
\text { (Rotterdam Criteria 2004 }\end{array}$ & $\begin{array}{c}\text { Androgen Excess Society } \\
\mathbf{2 0 0 6}\end{array}$ \\
\hline Includes all of the following & Includes two of the following & Includes all of the following \\
\hline $\begin{array}{l}\text { Clinical and biochemical } \\
\text { hyperandrogenism }\end{array}$ & $\begin{array}{l}\text { Clinical and biochemical } \\
\text { hyperandrogenism }\end{array}$ & $\begin{array}{l}\text { Clinical and biochemical } \\
\text { hyperandrogenism }\end{array}$ \\
\hline Menstrual dysunctionsl & Oligo-ovulation or annovulation & $\begin{array}{l}\text { Ovary dysfunction and polycystic } \\
\text { ovaries }\end{array}$ \\
\hline
\end{tabular}

ESHRE/ASRM = European Society for Human Reproduction and Embryology /American Society for Reproductive Medicine; $\mathrm{NIH} / \mathrm{NICH}=$ National Institute of Health / National Institute of Child Health and Human Disease.

The Rotterdam definition is the most widely used PCOS classification, and it is currently supported by most scientific societies and health authorities. ${ }^{13}$ The definition proposes that PCOS can be diagnosed in any woman presenting with at least two of the three following characteristics: clinical and/or biochemical hyperandrogenism, ovulatory dysfunction and PCOM. ${ }^{14}$ (The researchers defined polycystic ovarian morphology (PCOM) as either an ovary with 12 or more follicles, ranging in size from $2 \mathrm{~mm}$ to $10 \mathrm{~mm}$, in a single plane or an ovarian volume of more than $10 \mathrm{~mL}$ without a dominant follicle. the National Institute of Child Health and Human Development has an older definition that requires the presence of both hyperandrogenism and ovulatory dysfunction but does not consider ovarian morphology. ${ }^{15}$ Infertility is defined as the inability to conceive naturally after one year of regular unprotected intercourse. Most of the time, infertility is some degree of subfertility in which 1 in 7 couples need specialist help to conceive.

Subfertility can be either primary or secondary. Primary subfertility is a delay for a couple who have had no previous pregnancies; and, secondary subfertility is a delay for a couple who have conceived previously, although the pregnancy may not have been successful for example, miscarriage, and ectopic pregnancy. The chance to conceive depends on the length of sexual exposure, frequency of coitus, and couple's age. The normal, young aged couples have a $25 \%$ chance to conceive after 1 month of unprotected intercourse; $70 \%$ of the couple's conceive by 6 months, and $90 \%$ of the couples have a probability to conceive by 1 year. Only $5 \%$ of the couples will conceive after one and a half year or two years. ${ }^{16}$

According to the Center of Disease Control (CDC, 2013), the causes of female infertility can be divided into three broad categories including defective ovulation, transport and implantation. ${ }^{17}$ Polycystic ovarian disease (PCO) can lead to infertility because of an increased amount of testosterone and LH and decrease uptake of glucose by muscle, fat and liver cells resulting in the production of large amounts of insulin by the pancreas. Low FSH levels also hinder the production of eggs from the ovarian follicles, and lead to form fluid-filled ovarian cysts that eventually cover the whole ovaries and prevent conception.

PCOS is a complex disease, and treatment should include interventions to address the problems of infertility, hyperandrogenism, obesity, insulin resistance, and other features. ${ }^{18}$ Often a single intervention may not address this issue, and a combination of two may have a beneficial effect. The treatment options for infertility 
include lifestyle modification (diet and exercise), ovulation induction (clomiphene citrate $[\mathrm{CC}]$ and other medications like metformin, anastrozole, tamoxien, gonadotropins surgical, laparoscopic ovarian drilling (LOD), ovulation induction with homologous intrauterine insemination (IUI), in vitro fertilization (IVF). ${ }^{18-21}$

The aim and objective of our study was to study the effect of letrozole alone on induction of ovulation and clinical pregnancy in PCOD patients, to study the effect of letrozole in combination with HMG on induction of ovulation and clinical pregnancy in PCOD patients and to compare the effects of letrozole alone and letrozole in combination with HMG on induction of ovulation and clinical pregnancy in PCOD patients.

\section{METHODS}

The study was conducted in the department of Obstetrics and Gynaecology of Lalla Ded Hospital, GMC Srinagar, a tertiary care centre over a period of two years. It was a prospective observational study. Ethical clearance was obtained from the institutional ethical committee of the medical college. Written informed consent was obtained from all the participants of the study after explaining the risks and benefits of the planned treatment.

\section{Inclusion criteria}

Patients with age 20-35 years, patients with infertility lasting more than 1 year, male partner having semen analysis according to WHO 2010, no history of treatment by exogenous gonadotropins, patients receiving treatment for PCOD, normal hysterosalpingography (HSG) or laparoscopy, clomiphene resistant cases of PCOD, normal hormone (e.g. FSH, LH, estradiol (E2), testosterone $(\mathrm{T})$, insulin and prolactin) levels in the venous blood of all patients detected on the 2nd-4th days of menstruation were included in the study.

\section{Exclusion criteria}

Patients having history of ovarian surgery or complication with endometriosis or pelvic adhesions, patients complicated with liver, kidney and thyroid dysfunction, the presence of any infertility factor other than anovulatory PCOS such as hyper-prolactinemia, hypothalamic amenorrhea, premature ovarian failure and ovarian tumor were excluded from the study.

All the cases were PCOS infertility patients in line with the PCOS diagnostic criteria of the 2003 Rotterdam Conference, i.e. at least two of the following three were met 1) Ovulation abnormality (sporadic ovulation or no ovulation) occurred after continuous monitoring for two or more natural cycles; 2) the results of B ultrasound showed polycystic ovary; 3) Patients had hyperandrogenism or showed clinical manifestations of androgen excess, and those with androgen excess caused by other diseases such as adrenal hyperplasia, Cushing's syndrome and androgen-secreting tumors were excluded.

Demographic details namely age, duration of marriage, years of infertility and baseline serum levels of TSH, FSH, LH and prolactin were noted. A total of 150 consecutive patients were enrolled in the study and were randomly divided into two groups of 75 each. Group " $A$ " received letrozole in a dose of $2.5 \mathrm{mg}$ to $5 \mathrm{mg} / \mathrm{d} \mathrm{LE}$ was started orally starting on 3rd to 5th day of menstrual cycle for 5 consecutive days. Group " $B$ " received letrozole in a dose of 2.5 to $5 \mathrm{mg} /$ day starting on the $3 \mathrm{rd}$ to 5 th day of menstrual cycle for 5 consecutive days. Starting from the day of oral administration of letrozole, 75 IU HMG was injected intramuscularly on alternate days for 5 consecutive doses. Both the groups received treatment of ovulation induction for 4 to 6 cycles.

Starting from the 10th day of menstruation, the growth conditions of follicles and endometrium in the patients were monitored once every other day by transvaginal B ultrasound, and then daily when the average diameter of the follicles was $\geq 16 \mathrm{~mm}$. When the average diameter of follicles was $\geq 18 \mathrm{~mm}$, the endometrial thickness, number of mature follicles and diameter of the largest follicle were recorded.

The day when the size of at least one dominant follicle reached $18 \mathrm{~mm}$, ovulation was triggered by an intramuscular injection of 5,000-10,000 $\mathrm{U}$ of human chorionic gonadotropin (HCG). On the same day, the venous blood of patients was drawn to examine the $\mathrm{LH}$, $\mathrm{E} 2$ and $\mathrm{T}$ levels, who were then guided to have sexual intercourse within 24 hours. B ultrasound examination was performed again 48 hours after HCG injection to observe follicle rupture and single follicle ovulation. Ovulation was expected after $36 \mathrm{~h}$ of injection HCG, and it was confirmed by TVS.

Crenation of the follicle and appearance of fluid in the pouch of Douglas were considered to be the signs of rupture of follicle. If fetal heart beat was visible under transvaginal ultrasound on the 30th day after ovulation, the patients were diagnosed as clinical pregnancy. The only method for ultrasonography used was transvaginal, and it was done by the same operator/observer, using the same ultrasound equipment throughout the study. The power of transvaginal probe used was $7.5 \mathrm{MHz}$.

\section{Statistical method employed}

The recorded data was compiled and entered in a spreadsheet (Microsoft Excel) and then exported to data editor of SPSS Version 20.0 (SPSS Inc., Chicago, Illinois, USA). Statistical software SPSS and Microsoft Excel were used to carry out the statistical analysis of data. Descriptive statistics of data including percentages and means were reported. Values for continuous data were expressed as mean \pm SD and categorical variables as proportions. Two groups will be compared by analysis of 
variance, and intergroup comparisons will be performed by the SNK method. The numerical data will be subjected to $\chi 2$ test for $\mathrm{R} \times \mathrm{C}$ table. When the theoretical frequency of at least one cell is lower than the expected value, the Fisher's exact test will be used $\mathrm{p}<0.05$ will be considered statistically significant.

\section{RESULTS}

The study comprised of 150 couples (568 cycles in total), who were randomly divided into two groups of 75 each. Group "A" received letrozole (LE) in a dose of $2.5 \mathrm{mg}$ to $5 \mathrm{mg} / \mathrm{d}$. LE was started orally starting on 3rd to 5 th day of menstrual cycle for 5 consecutive days. Group "B" received letrozole in a dose of 2.5 to $5 \mathrm{mg} /$ day starting on the 3 rd to 5 th day of menstrual cycle for 5 consecutive days. Starting from the day of oral administration of letrozole, 75 IU HMG was injected intramuscularly on alternate days for 5 consecutive doses. Table 2 compares the general characteristics of Group A and Group B.
Table 3 depicts the initial reproductive hormone levels in both groups. Evaluation of the baseline characteristics of the groups showed that there were no significant differences in age $(p>0.05)$, infertility time $(p>0.05)$ or body mass index $(p>0.05)$. Moreover, the base serum hormone levels (luteinizing hormone, FSH and E 2) were not significantly different between the 2 groups either (Table 3).

The respective p-values for all the parameters were more than 0.05 indicating that no significant differences between the groups and both the groups were comparable. The Group A (LE group) had the most completed cycle (310 cycles), $157(52.3 \%)$ of which had ovulation. The Group B (LE+HMG) group completed the fewest cycles (258 cycles), with $168(65.1 \%)$ of them ovulating. This difference was statistically significant $(\mathrm{p}<0.05)$ (Table 4).

Table 2: General characteristics (Mean \pm SD of age, duration of infertility and BMI).

\begin{tabular}{|lllll|}
\hline Group & No. of patients $(\mathbf{N})$ & Age (years) & $\begin{array}{l}\text { Infertility duration } \\
\text { (years) }\end{array}$ & BMI $\left(\mathbf{K g} / \mathbf{m}^{2}\right)$ \\
\hline Group A & 75 & $26.7 \pm 2.2$ & $3.24 \pm 1.0$ & $22.45 \pm 1.7$ \\
\hline Group B & 75 & $26.9 \pm 2.2$ & $3.4 \pm 1.0$ & $22.84 \pm 1.7$ \\
\hline P-value & - & $>0.05$ & $>0.05$ & $>0.05$ \\
\hline
\end{tabular}

Table 3: Initial reproductive hormone levels.

\begin{tabular}{|llllll|}
\hline Group & No. of patients (N) & FSH (IU/l) & LH (IU/l) & E2 (pg/l) & T (mmol/l) \\
\hline Group A & 75 & $7.05 \pm 1.5$ & $5.7 \pm 0.8$ & $56.95 \pm 8$ & $1.50 \pm 0.5$ \\
\hline Group B & 75 & $7.3 \pm 1.4$ & $5.6 \pm 0.8$ & $57.88 \pm 8$ & $1.57 \pm 0.5$ \\
\hline P-value & - & $>0.05$ & $>0.05$ & $>0.05$ & $>0.05$ \\
\hline
\end{tabular}

Table 4: Ovulation induction cycles.

\begin{tabular}{|lllll|}
\hline Group & No. of patients (N) & Completed cycle & Ovulated cycle (\%) & Single follicle ovulation cycle \\
\hline Group A & 75 & 310 & $157(52.3 \%)$ & 75 \\
\hline Group B & 75 & 258 & $168(65.1 \%)$ & 110 \\
\hline P-value & - & - & $<0.001$ & - \\
\hline
\end{tabular}

Table 5: Monitoring on HCG injection day

\begin{tabular}{|llllll|}
\hline Group & $\begin{array}{l}\text { No. of patients } \\
(\mathbf{N})\end{array}$ & $\begin{array}{l}\text { Endometrial thickness } \\
(\mathbf{m m})\end{array}$ & $\begin{array}{l}\text { No. of mature } \\
\text { follicles }\end{array}$ & $\begin{array}{l}\text { Maximum follicle } \\
\text { diameter (mm) }\end{array}$ & OHSS (Case) \\
\hline Group A & 75 & $9.02 \pm 0.66$ & $1.14 \pm 0.8$ & $19.3 \pm 1.2$ & 2 \\
\hline Group B & 75 & $11.5 \pm 1.2$ & $2.1 \pm 1.3$ & $18.83 \pm 1.17$ & 4 \\
\hline P-value & - & $<0.001$ & $<0.001$ & $>0.05$ & $>0.05$ \\
\hline
\end{tabular}

Table 6: Hormone levels on HCG injection day (Mean \pm SD)

\begin{tabular}{|lllll|}
\hline Group & No. of patients $(\mathbf{N})$ & LH (IU/L) & E2 $(\mathbf{p g} / \mathbf{l})$ & T (mmol/L) \\
\hline Group A & 75 & $29.85 \pm 5.7$ & $309.9 \pm 75.4$ & $1.43 \pm 0.5$ \\
\hline Group B & 75 & $29.9 \pm 5.8$ & $617 \pm 84.4$ & $1.40 \pm 0.5$ \\
\hline P-value & - & $>0.05$ & $<0.001$ & $>0.05$ \\
\hline
\end{tabular}


Table 7: Effects of different regimens on pregnancy.

\begin{tabular}{|llllll|}
\hline Group & $\begin{array}{l}\text { No. of patients } \\
(\mathbf{N})\end{array}$ & $\begin{array}{l}\text { Clinical pregnancy } \\
(\%)\end{array}$ & Abortion & $\begin{array}{l}\text { Multiple } \\
\text { pregnancy }\end{array}$ & $\begin{array}{l}\text { Average } \\
\text { treatment cycle }\end{array}$ \\
\hline Group A & 75 & $22(29.3)$ & 3 & 3 & $3.97 \pm 0.9$ \\
\hline Group B & 75 & $41(54.7)$ & 3 & 7 & $2.8 \pm 1$ \\
\hline P-value & - & $<0.05$ & - & - & $>0.05$ \\
\hline
\end{tabular}

On HCG injection day, both the endometrial thickness $(11.5 \pm 1.2)$ and number of mature follicles $(2.1 \pm 1.3)$ of the Group B were significantly higher than those of Group A $(\mathrm{p}<0.001)$, but the follicle diameters were similar ( $p>0.05)$ (Table 5). Both the groups suffered from OHSS, but the incidence rates were similar $(\mathrm{p}>0.05)$. On HCG injection day, T level hardly changed, LH and E2 levels significantly increased, and there were no significant intergroup differences between LH levels.

The Group B $(617 \pm 84.4$ pg/l) had significantly higher E2 level than those of Group A $(309.9 \pm 75.4 \mathrm{pg} / \mathrm{l})(\mathrm{p}<0.05)$ (Table 6).

The pregnancy rate of the Group B was $54.7 \%$, which was significantly higher than that of the Group A (29.3\%) $(p<0.05)$ (Table 7). There were no statistically significant differences in the abortion rate and multiple pregnancy rate between the groups $(p>0.05)$. The average medication cycle of the Group B group was significantly shorter than that of the Group A $(\mathrm{p}<0.05)$.

\section{DISCUSSION}

Polycystic ovary syndrome (PCOS), characterized by ovulatory dysfunction and hyperandrogenism, is the most common cause of infertility in women. ${ }^{3}$ The diagnosis of PCOS has life-long implications with increased risk for infertility, metabolic syndrome, type 2 diabetes mellitus, and possibly cardiovascular disease. It should be considered in any adolescent girl with hirsutism, persistent acne, menstrual irregularity, or obesity. Approximately two-thirds of patients with PCOS, whether adolescent or adult, have anovulatory symptoms. ${ }^{14,21 .}$

Clomiphene citrate (CC) is the most commonly used pharmacologic agent to induce ovulation in these women, but some women fail to conceive with this therapy. During the past decade, both insulin sensitizers, such as metformin, and aromatase inhibitors, have been used for ovulation induction in women who fail to conceive with CC. Aromatase inhibitors are a class of drugs that block estrogen biosynthesis, thereby reducing negative estrogenic feedback at the pituitary. ${ }^{23}$

As the gene product of CYP19, aromatase can act on androstenedione generated from the adrenal cortex of adipose tissues to form estrone and testosterone in ovarian tissues to produce androstenedione, and then transform a part of androstenedione into estrone. ${ }^{24,25}$ Theoretically, Letrozole may be superior to Clomiphene citrate because it has no peripheral anti-estrogen effect. Al-Omari et al. found that the ovulation rate after using $2.5 \mathrm{mg}$ LE reached $84.4 \%$ and the cycle pregnancy rate was $19 \% .{ }^{26}$ Sun et al. reported that LE with a dose of 5.0 $\mathrm{mg} / \mathrm{d} \times 5 \mathrm{~d}$ had better follicle development and higher pregnancy rate than those of $2.5 \mathrm{mg} / \mathrm{d} \times 5 \mathrm{~d} \mathrm{LE}$, but increasing the dose to $7.5 \mathrm{mg} / \mathrm{d}$ did not effectively improve the treatment outcomes. ${ }^{27}$

In present study, evaluation of the baseline characteristics of the groups showed that there were no significant differences in age $(p>0.05)$, infertility time $(p>0.05)$ or body mass index $(\mathrm{p}>0.05)$. Moreover, the base serum hormone levels (luteinizing hormone, FSH and E2) were not significantly different between the 2 groups either. Reproductive age is the most critical factor in determining the outcome of female infertility treatment.

A significant decline in fecundity occurs in women starting at the age of 35 years. ${ }^{28}$ Several factors account for obstacles and failures of fertility treatment with advancing female age including poor oocyte quality, reduction in follicular recruitment and follicular response to internal and external gonadotropins, and the decline in endometrial receptivity. ${ }^{28}$ In this study, the mean age at presentation for Group A and Group B was 26.7( \pm 2.2$)$ years and 26.9( \pm 2.2$)$ years respectively.

Obesity is a growing public health concern in the United States and has been shown to negatively affect fertility, with a significant increase in anovulation29. The assisted reproductive technologies literature indicates obesity has been associated with lower oocyte yields after controlled ovarian hyperstimulation, lower clinical pregnancy rates, and an increase in pregnancy loss. Increasing BMI may also negatively affect ovulation rates with $\mathrm{CC}$, especially in women with PCOS. ${ }^{29}$ One study of 44 CC-resistant PCOS patients showed no difference in response to letrozole based on BMI. However, that study included women with a small range of BMIs: $293.59 \mathrm{~kg} / \mathrm{m}^{2}$. It is currently unclear if BMI affects the response to OI with letrozole in women with infertility diagnoses beyond PCOS. ${ }^{29}$ In current study, the mean BMI at presentation for Group A and Group B was $22.45( \pm 1.7) \mathrm{kg} / \mathrm{m}^{2}$ and $22.84( \pm 1.7) \mathrm{kg} / \mathrm{m}^{2}$ respectively.

In this study, the Group A (LE group) had the most completed cycle (310 cycles), $157(52.3 \%)$ of which had ovulation. The Group B (LE + HMG) group completed 
the fewest cycles (258 cycles), with $168(65.1 \%)$ of them ovulating. This difference was statistically significant $(\mathrm{P}<0.05)$. In this study, the pregnancy rate of the Group B was $54.7 \%$, which was significantly higher than that of the Group A $(29.3 \%)(\mathrm{p}<0.05)$.

The observations of Badawy et al who reported a pregnancy rate of $23.7 \%$ with the letrozole + gonadotropin group $^{30}$ However, in their study the gonadotropins were used in a sequential manner in the letrozole group. Jee et al reported pregnancy rates for letrozole to be $18.2 \%$ in combination with gonadotropins in their prospective pilot study. ${ }^{31}$ The study was, however, nonrandomized, with the groups being assigned as per the couple's preferences; also, the couples who were recruited did not exclusively have unexplained infertility. The pregnancy rates observed in both the abovementioned studies were lower than those observed in our study.

This may be attributed to the different dose of gonadotropin used in these studies. Dhaliwal et al in their study compared minimal stimulation with the standard conventional stimulation protocol, along with IUI in patients with unexplained infertility and CC failures. ${ }^{32}$ The pregnancy rate observed by them with the minimal stimulation and conventional protocol was $14.63 \%$ and $18.75 \%$, respectively. Barroso et al carried out a prospective, randomized, clinical trial in couples with unexplained infertility in which the establishment of pregnancy was a secondary end point owing to the relatively low sample size and statistical power for assessing such outcome. ${ }^{33}$

Nevertheless, there were no differences in the clinical pregnancy rates among the groups $(23.8 \%$ in the letrozole group vs. $20 \%$ in the CC group). Mitwally et al achieved pregnancy rate of $19.6 \% .^{34}$ Their study, however, comprised couples with all kinds of infertility factors. Another study conducted by the same author in couples with unexplained infertility to test the hypothesis that the use of the AI letrozole in conjunction with FSH for controlled ovarian stimulation would decrease the dose of gonadotrophins required for controlled ovarian stimulation similar to CC with FSH. They found a higher pregnancy rate with the letrozole+gonadotropins group $(22.2 \%){ }^{35}$ The observations in our study were, however, comparable to those seen in a study by Zhihua Chen et al and Fadia J Alizzi, who found the pregnancy rates of LE+HMG group to be $55.7 \%$ and $59.4 \%$, respectively. ${ }^{36,37}$

In our study, the maximum follicular size in group A was $19.3 \pm 1.2 \mathrm{~mm}$ while in group $\mathrm{B}$, it was $18.83 \pm 1.17 \mathrm{~mm}$, the difference between the two groups being statistically insignificant. However, the number of mature follicles per cycle was higher in group B $(2.1 \pm 1.3)$ as compared to group A (1.14 \pm 0.8$)$, the difference between the two being highly significant statistically ( $\mathrm{p}$-value $<0.001$ ).
Badawy et al, observed the follicle number being $2.6 \pm 0.43$ in the letrozole group in their study. Jee et al reported similar findings in their study with significantly lesser number of follicles observed in the letrozole group (3.2 \pm 1.7 vs. $5.6 \pm 2.4){ }^{30,31}$ This is also in agreement with the results of Tehrani et al..$^{38}$ Their study, which was a prospective randomized trial, recruited 140 patients with unexplained infertility who then received either letrozole or $\mathrm{CC}+$ gonadotropin as per randomization. The number of mature follicles $(1.8 \pm 0.7$ vs. $2.46 \pm 2.3 ; \mathrm{P}=0.042)$ were significantly lower in the letrozole group. In another study by Jee et al, the mean number of dominant follicles in the letrozole $+\mathrm{hMG}$ group were $3.2 \pm 1.7 .{ }^{31}$

In the present study, the mean endometrial thickness was greater in Group B $(11.5 \pm 1.2 \mathrm{~mm})$ than in Group A $(9.02$ \pm 0.66 ), the difference being statistically significant (pvalue $<0.001$ ). Fang $\mathrm{XU}$ did not find statistically significant difference between endometrial thickness between the two groups. ${ }^{39}$ Malhotra et al did a prospective randomized trial on letrozole alone or letrozole gonadotropin combination as the first line for superovulation in women with unexplained infertility undergoing intrauterine insemination and went out in a conclusion that better number of follicles and improved ET result in higher pregnancy rate in letrozole-human menopausal gonadotropin (HMG) protocol in comparison to letrozole alone protocol and letrozole-HMG should be preferred over letrozole as the first line for superovulation in unexplained infertility. ${ }^{40}$

Badawy et al. compared the combination of letrozole and gonadotropins to that of $\mathrm{CC}$ and gonadotropins combination. ${ }^{30}$ Endometrial thickness, in their study, was $9.1 \pm 0.42 \mathrm{~mm}$ in the letrozole group while in the CC group, it was $8.9 \pm 0.62 \mathrm{~mm}$. This, however, is in contrast to the results of a prospective study conducted by Barroso et al who reported a significantly higher endometrial thickness with letrozole and gonadotropin combination $(9.5 \pm 1.5 \mathrm{~mm})$ as compared to $\mathrm{CC}$ and gonadotropin combination $(7.3 \pm 1.1 \mathrm{~mm}){ }^{33}$ Similar results were also reported by Sh Tehrani et al who found a statistically significant difference between the endometrial thickness of the two groups; it was higher in the letrozole group as compared to $\mathrm{CC}$ and gonadotropin combination $(9.7 \pm 1.6 \mathrm{~mm}$ vs. $7.8 \pm 2 \mathrm{~mm} ; \mathrm{P}<0.001) .{ }^{38}$

There were no statistically significant differences in the abortion rate and multiple pregnancy rate between the groups $(p>0.05)$. All the abortions in both the groups were early abortions, which may be due to poor endometrial receptivity or some genetic factor. In the present study, there was one ectopic pregnancy in the Group B. The woman with ectopic pregnancy had a history of ectopic pregnancy in the past, which may be a risk for recurrence of ectopic pregnancy. There was only one ectopic pregnancy in the letrozole $+\mathrm{hMG}$ group in a study conducted by Jee et al. ${ }^{31}$. 
In our study, multiple pregnancies observed in Group A and Group B were 3 and 7 respectively, which were of borderline significance. This may be attributed to the low-dose gonadotropins used in Group B. Human menopausal gonadotropin (HMG), which contains follicle stimulating hormone (FSH) and luteinizing hormone (LH), can secrete gonadotropin to promote follicle maturation, so as to stimulate ovulation and to accelerate the development of corpus luteum.

Nevertheless, HMG can lead to multiple follicle development or cause multiple pregnancy and ovarian hyperstimulation syndrome (OHSS), so it is often used in combination with $\mathrm{CC}$ or $\mathrm{LE}$ in case of ineffective ovulation induction. ${ }^{41,42}$. Alternatively, high-dose HMG is used for ovarian hyperstimulation in combination with CC52. Both the groups in this study suffered from OHSS, but the incidence rates were similar. Two regimens using HMG are used currently for ovulation induction: lowdose escalation and high dose descending. The low-dose escalation regimen is most commonly used at present, which can reduce the incidence rates of OHSS and multiple follicles by timely adjusting the HMG dosage according to B ultrasound results. ${ }^{36}$ It is well-documented that single-use or high-dose HMG may lead to multiple pregnancy and OHSS, so it is recommended to minimize the dosage of HMG. ${ }^{41,42}$.

Although use of low-dose gonadotropins yields significantly fewer number of oocytes compared to conventional stimulation, a higher percentage of mature oocytes are produced. Availability of better quality oocytes and more receptive endometrium can assure good outcome even with the use of low-dose gonadotropins. The controlled ovarian stimulation regime used in this study was easy to administer, required less intensive monitoring and fewer medications, with very little risk of OHSS and multiple gestation. We herein assessed the effects of LE in combination of small-dose injection of HMG on the ovulation induction of PCOS patients, and found the combination regimen had obvious advantages.

\section{CONCLUSION}

In conclusion, the regimen using LE in combination with low-dose injection of HMG every other day had a satisfactory effect on ovulation, short medication cycle and high clinical pregnancy rate, which provides a promising option for the treatment of patients with PCOS infertility. The regimen has many advantages, but ultrasound and related laboratory examinations are needed to monitor various indices during the treatment, thus increasing the cost of treatment. Furthermore, some patients have poor compliance in clinical practice. A large sample- size and multi-center research is required to confirm the application value of the regimen in patients with ovulatory disorder infertility.

\section{ACKNOWLEDGMENTS}

Authors acknowledge the immense help received from the scholars whose articles are cited and included in references of this manuscript. The authors are also grateful to authors/editors/publishers of all those articles, journals and books from where the literature for this article has been reviewed and discussed.

Funding: No funding sources

Conflict of interest: None declared

Ethical approval: The study was approved by the Institutional Ethics Committee

\section{REFERENCES}

1. Azziz, R. The androgen excess and PCOS society criteria for the polycystic ovary syndrome: the complete task force report. Fertil Steril. 2009;91:45688.

2. Asuncion M. A prospective study of the prevalence of the polycystic ovary syndrome in unselected Caucasian women from Spain. J Clin Endocrinol Metab. 2000;85:2434-8.

3. Azziz R. The prevalence and features of the polycystic ovary syndrome in an unselected population. J Clin Endocrinol Metab. 2004;89:27459.

4. Kandarakis DE. A survey of the polycystic ovary syndrome in the Greek island of Lesbos: hormonal and metabolic profile. J Clin Endocrinol Metab. 1999;84:4006-11.

5. Yildiz BO, Bozdag G, Yapici Z, Esinler I. Yarali H. Prevalence, phenotype and cardiometabolic risk of polycystic ovary syndrome under different diagnostic criteria. Hum Reprod. 2012;27:3067-73.

6. Franks S. Polycystic ovary syndrome. N Engl J Med. 1995;333(13):853-61.

7. Mohd M, Maqbool M, Dar MA, Mushtaq I. Polycystic ovary syndrome, a modern epidemic: An overview, J Drug Delivery Therapeutics. 2019;9(3):641-4.

8. Nidhi R, Padmalatha V, Nagarathna R, Amritanshu $\mathrm{R}$. Prevalence of polycystic ovarian syndrome in Indian adolescents. J Pediatr Adolesc Gynecol. 2011;24:223-7.

9. Stein IF. Leventhal ML. Amenorrhea associated with bilateral polycystic ovaries. Am J Obstet Gynecol. 1935;29:181-91.

10. World Health Organization. The ICD10 classification of mental and behavioural disorders: Clinical descriptions and diagnostic guidelines. (World Health Organization, Geneva, 1992).

11. Radosh L. Drug treatments for polycystic ovary syndrome. Am Fam Physician. 2009;79:671-6.

12. Dewailly D. Definition and significance of polycystic ovarian morphology: a task force report from the androgen excess and polycystic ovary syndrome society. Hum Reprod Update. 2014;20:334-52. 
13. Steering Committee of the National Institutes of Health Evidence-Based Methodology Workshop on Polycystic Ovary Syndrome. Evidence-based Methodology Workshop on Polycystic Ovary Syndrome. Final Report. Available at https://prevention.nih.gov/docs/programs/pcos/Final Report.pdf (National Institute of Health, Bethesda, MD, USA, 2012). Accessed on 10 July 2020.

14. The Rotterdam ESHRE/ASRM-sponsored PCOS consensus workshop group. Revised 2003 consensus on diagnostic criteria and long-term health risks related to polycystic ovary syndrome (PCOS). Hum Reprod. 2004;19:41-7.

15. Zawadzki JK, Dunaif A. In polycystic ovary syndrome (eds Dunaif, A., Givens JR, Haseltine FP and Merriam GR.) (Blackwell Scientific Publications, Boston, MA, USA, 1992). 1992;377-84

16. Anwar S, Anwar A. Infertility: a review on causes, treatment and management. Women's Health and Gynecology. 2016;7:67-9.

17. Centers for Disease Control and Prevention. Infertility FAQs. 2013.

18. Thomas S, Sudharshini S. Polycystic ovarian syndrome: Treatment options for infertility. Curr Med Issues. 2019;14:87-93.

19. Bhatnagar AS. The discovery and mechanism of action of letrozole published correction appears in Breast. Cancer Res Treat. 2008;112(2):385.

20. Dhaliwal LK, Suri V, Gupta KR, Sahdev S. Tamoxifen: an alternative to clomiphene in women with polycystic ovary syndrome. J Hum Reprod Sci. 2011;4(2):76-9.

21. Lebbi I, Temime R, Fadhlaoui A, Feki A. Ovarian Drilling in PCOS: Is it really useful? Front Surg. 2015;2:30.

22. King J. Polycystic ovary syndrome. J Midwifery Womens Health. 2006;51:415-22.

23. Misso ML, Wong JL, Teede HJ, Hart R, Rombauts L, Melder AM, et al. Aromatase inhibitors for PCOS: A systematic review and meta-analysis. Hum Reprod Update. 2012;18:301-12.

24. Bacci M, Giannoni E, Fearns A, Ribas R, Gao Q, Taddei ML, et al. miR-155 drives metabolic reprogramming of ER+breast cancer cells following long-term estrogen deprivation and predicts clinical response to aromatase inhibitors. Cancer Res. 2016;76(6):1615-26

25. Ghosh D, Lo J, Egbuta C. Recent Progress in the Discovery of Next Generation inhibitors of aromatase from the structure- function perspective. $\mathbf{J}$ Med Chem. 2016;59(11):5131-48.

26. Al-Omari WR, Sulaiman WR, Al-Hadithi N. Comparison of two aromatase inhibitors in women with clomipheneresistant polycystic ovary syndrome. Int J Gynaecol Obstet. 2004;85(3):289-91.

27. Sun XL, Zhang YQ, Jiang GH. Therapeutic effects of different doses of letrozole on ovulation induction of patients with polycystic ovarian syndrome. J Nantong Uni (Med Sci). 2011;31(6):494-95.
28. Bedaiwy MA, Shokry M, Mousa N. Letrozole cotreatment in infertile women 40 years old and older receiving controlled ovarian stimulation and intrauterine insemination. Fertil Steril. 2009;91:2501-07.

29. McKnight KK, Nodler JL, Cooper JJ. Body mass index-associated differences in response to ovulation induction with letrozole. Fertil Steril. 2011;96:1206e8.

30. Badawy A, Elnashar A, Totongy M. Clomiphene citrate or aromatase inhibitors combined with gonadotropins for superovulation in women undergoing intrauterine insemination: a prospective randomised trial. J Obstet Gynaecol. 2010;30:61721.

31. Jee BC, Ku SY, Suh CS, Kim KC, Lee WD, Kim $\mathrm{SH}$. Use of letrozole versus clomiphene citrate combined with gonadotropins in intrauterine insemination cycles: a pilot study. Fertil Steril. 2006;85:1774-7.

32. Dhaliwal LK, Sialy RK, Gopalan S, Majumdar S. Minimal stimulation protocol for use with intrauterine insemination in the treatment of infertility. J Obstet Gynaecol Res. 2002;28:295-9.

33. Barroso G, Menocal G, Felix H, Ruiz JC, Arslan M, Oehninger S. Comparison of the efficacy of the aromatase inhibitor letrozole and clomiphene citrate as adjuvants to recombinant follicle-stimulating hormone in controlled ovarian hyperstimulation: A prospective, randomized, blinded clinical trial. Fertil Steril. 2006;86:1428-31.

34. Mitwally MF, Biljan MM, Casper RF. Pregnancy outcome after the use of an aromatase inhibitor for ovarian stimulation. Am J Obstet Gynecol. 2005;192:381-6.

35. Mitwally MF, Casper RF. Aromatase inhibition reduces gonadotrophin dose required for controlled ovarian stimulation in women with unexplained infertility. Hum Reprod. 2003;18:1588-97.

36. Chen Z, Zhang M, Qiao Y, Yang J. Effects of letrozole in combination with low-dose intramuscular injection of human menopausal gonadotropin on ovulation and pregnancy of 156 patients with polycystic ovary syndrome. Pak J Med Sci. 2016;32(6):1434-8.

37. Alizzi FJ. Letrozole with or without gonadotropin as a first-line ovulation induction in anovulatory infertile women due to polycystic ovary syndrome AJPCR. 2018;11(8):59-65.

38. Nejad TE, Abidiasl Z, Rashidi BH, Nekoo AE, Shariat M, Amirchaghmaghi E. Comparison of the efficacy of aromatase inhibitor letrozole and clomiphen citrate gonadotropins in controlled ovarian hyperstimulation: a prospective, simply randomized, clinical trial. J Assist Reprod Genet. 2008;25:187-90.

39. Bu-fang XU, Guang-yan Wang, Wei-min Fan, Qian Chen, Ai-jun Zhang. Which is the best protocol of ovarian stimulation prior to artificial insemination by donor. J Reprod Contracep. 2014;25(1):41-8. 
40. Malhotra N, Karmakar D, Kumar S. Letrozole alone or letrozole gonadotropin combination as first line for superovulation in women with unexplained infertility undergoing intrauterine insemination (IUI): a prospective randomized trial. Fertil Steril. 2012;98(3):S258.

41. Yun BH, Chon SJ, Park JH, et al. Minimal stimulation using gonadotropin combined with clomiphene citrate or letrozole for intrauterine insemination. Yonsei Med J. 2015;56(2):490-6.

42. Xi W, Liu S, Mao H, Yang Y, Xue X, Lu X. Use of letrozole and clomiphene citrate combined with gonadotropins in clomiphene-resistant infertile women with polycystic ovary syndrome: a prospective study. Drug Des Devel Ther. 2015;9:6001-8.

Cite this article as: Ahmad K, Muzaffar U, Bashir S, Jabeen F. Effects of letrozole alone or letrozole in combination with low-dose intramuscular injection of human menopausal gonadotropin on ovulation and pregnancy of 150 patients with polycystic ovary syndrome. Int J Reprod Contracept Obstet Gynecol 2021;10:164-72. 